\title{
Resistência ovina frente a nematoides gastrintestinais
}

\author{
Amarilho-Silveira, F. ${ }^{@} ;$ Brondani, W.C. ${ }^{\text {; }}$ Motta, J.F. ${ }^{1}$; Ferreira, O.G.L. ${ }^{1}$ e Lemes, J.S. ${ }^{2}$ \\ Universidade Federal de Pelotas (UFPel). Pelotas-RS. Brasil. \\ ¿Universidade Federal de Santa Maria (UFSM/CESNORS). Palmeira das Missões-RS. Brasil.
}

\section{PalaVRas chaVe adicionals}

\section{Helmintos.}

Marcadores moleculares.

Loci controladores de características quantitativas.

Polimorfismos de nucleotídeo único.

\section{ADDITIONAL KEYWORDS}

Helminths.

Molecular markers.

Quantitative trait Loci.

Single nucleotide polimorphisms.

\section{INFORMACIÓN}

Cronología del artículo.

Recibido/Received: 7.1.2015

Aceptado/Accepted: 15.5.2015

On-line: 14.7.2015

Correspondencia a los autores/Contact e-mail:

amarillo@zootecnista.com.br

\section{RESUMO}

A habilidade dos ovinos adquirirem e expressarem imunidade frente à ação de nematoides gastrintestinais é controlada geneticamente e varia substancialmente entre as diferentes raças, bem como entre os indivíduos de uma mesma raça. A idade, estado nutricional, e as transições fisiológicas têm grande interferência sobre a susceptibilidade; em fases que exigem mais nutrientes, voltado principalmente para a produção, há uma incidência maior. O método de avaliação de resistência mais utilizado é a quantificação de ovos por grama de fezes em determinadas épocas de desafio. Porém devido alguns aspectos isolados desse método vem sendo estudado marcadores a nível genético. O estudo de tecnologias em prol da produção ovina é de suma importância para o crescimento da atividade, onde pelo processo de melhoramento de características especificas, como a resistência a verminose, não acarretaria numa diminuição da produtividade. Outro ponto a se considerar é que deve ser dado enfoque a tecnologias de produção com baixo impacto ambiental e com uma diminuição de riscos residuais nos produtos destinados a o consumo humano.

\section{Resistance against sheep gastrointestinal nematodes}

\section{SUMMARY}

The ability of sheep acquiring immunity and express the action against of gastrointestinal nematodes is genetically controlled and varies substantially between different breeds, as well as between individuals of the same breed. The age, nutritional status and physiological transitions have great interference on the susceptibility; in phases what demand more nutrients, primarily geared to production, there is a greater incidence is the quantification of eggs per gram of feces in certain times of challenge. However due to some isolated aspects this method have been studied the genetic markers. The study of technologies for sheep production is of prime importance for the growth of activity, where the process of improvement of specific characteristics, such as resistance to worms, would not decrease in productivity. Another point to consider is that it should be given focus to production technologies with low environmental impact and with a decrease of residual risks in products intended for human consumption.

\section{INTRODUÇÃO}

As verminoses representam o maior e mais grave problema sanitário concernente à ovinocultura, podendo inviabilizar economicamente a criação. As perdas produtivas devido ao parasitismo são duas vezes o custo direto com tratamento anti-hemintico e perdas produtivas por outras doenças e em casos extremos, a morte (Miller et al., 2012).

Problema que se agrava pela pressão de seleção dos helmintos resistentes aos fármacos encontrados no mercado. Estratégias para contornar esses estão sendo estudadas em larga escala, das quais podemos citar: manejo de potreiros; identificação de categorias susceptíveis e raças resistentes; uso de fungos nema- tófagos na dieta; suplementos alimentares com antihelmínticos, fitoterapia, descontaminação das pastagens com o uso de outras espécies de herbívoros, e até mesmo o pastejo consorciado com essas mesmas (Amarante, 2009). Assim, Cordeiro (2008), em trabalho com fungos nematófagos, encontrou resultados significativos no controle de nematoides com consideráveis reduções de larvas infectantes. Já Almeida et al. (2003), observaram redução superior a $95 \%$ do número de larvas com utilização de extrato de Cymbopogon citratus e de Digitaria insularis. O pastejo integrado com diferentes espécies de ruminantes é outra ferramenta com ótimos resultados, onde parasitas com especificidade para uma determinada espécie, quando ingerida a larva infectante por outra, a mesma será destruída (Amarante, 2009). 
O método Famacha é uma ferramenta de tratamento seletivo que consiste da comparação de diferentes tonalidades, de vermelho-rosado até o branco pálido da conjuntiva, representada respectivamente com os números de 1 a 5 e comparados com o cartão guia desenvolvido para utilização no campo, onde 1 hematócrito de $28 \%$ e 5 de $12 \%$ a baixo (Molento et al., 2004). Uma das principais vantagens deste método é a possibilidade da identificação de animais que apresentam algum tipo de anemia, assumindo a condição de infecção pelo Haemonchus contortus (Molento, 2009).

Ovinos selecionados para baixa contagem de ovos por grama de fezes (OPG) mostram grandes reduções de eliminação de ovos nas fezes quando infectados por parasitos gastrintestinais, logo assim a seleção para essa característica surtiria não só numa menor quantidade de nematoides no animal, mas uma redução na contaminação ambiental (Kemper et al., 2010).

A dependência do controle dos parasitos gastrintestinais através do uso de fármacos aumenta a pressão de seleção dos helmintos resistentes aos mesmos encontrados no mercado. Assim, Silveira et al. (2013), ao testarem três vermífugos (Abamectina, Moxidectina e Closantel+Albendazol) em um rebanho criado intensivamente não verificaram eficiência de nenhum dos tratamentos testados. Do mesmo modo, Barbosa et al. (2013) identificaram $100 \%$ de eficiência em apenas um, de 9 princípios ativos anti-helmínticos testados. Os autores atribuíram este resultado ao fato de ser o monopantel uma molécula nova no mercado e restritamente utilizada até o momento, de modo que ainda não há relatos de resistência helmíntica no Brasil.

É possível especular que a pressão seletiva imposta por tratamento anti-helmíntico tem efeitos semelhantes, as ações imunológicas do hospedeiro resistente frente à população de parasitas. Após vários anos de uso generalizado de medicamentos para o controle de infecções parasitárias, o aumento prevalência de nematódeos resistentes agora ameaça a produção animal em várias partes do mundo. $\mathrm{O}$ uso contínuo de drogas anti-helmínticas não elimina os parasitas, principalmente porque a maiorias das populações de nematoides estão em refúgios (por exemplo, ovos e larvas no pasto, no interior de animais assintomáticos ou animais dentro de outras espécies hospedeiras), e, portanto, não submetidos à seleção de drogas. Além disso, a associação genética presente nas populações em refúgios começou a fornecer continuamente mutações que conferem resistência aos medicamentos, que eventualmente se tornaram fixa (Molento et al., 2011). A situação é ainda mais complicada pela, geralmente, baixa estrutura genética das populações de parasitas e suas altas taxas de mutação (Nunes et al., 2013).

Outra característica importante do aumento de resistência anti-helmíntica é que levou décadas para se tornar um grave problema de produção. Parece que as mesmas populações em refúgios também funcionavam como uma reserva de material genético à pressão seletiva da droga que retardaram o processo de aumento de resistência. Essa hipótese é reforçada pela expectativa de que uma baixa relevância, na interação restrita entre parasito e hospedeiro, teria ocasionado na rápida erradicação ou resistência de ambos (Doeschl-Wilson e Kyriazakis, 2012). Portanto, dadas os diferentes resultados que o melhoramento para resistência ou resiliência pode ter sobre as populações de parasitas que seria útil e mais sustentável para combinar ambos os recursos. $\mathrm{Na}$ verdade, melhoramento para resistência pode ser mais eficaz no curto prazo, especialmente dada a sua maior herdabilidade em comparação com traços de resiliência (Bishop, 2012). Além disso, a seleção de populações de parasitas mais virulentos pode progredir lentamente, à semelhança do que aconteceu com a resistência anti-helmíntica. No entanto, a resistência vai ser uma característica importante, já que é improvável que ela acabará por levar à erradicação desses nematoides altamente prevalentes e de longo espectro (McManus et al., 2014).

O objetivo desta revisão é elucidar alguns fatores de produção e identificação de animais com características de resistência a nematoides gastrointestinais, logo assim, no futuro, poder ser usado esse material como fonte teórica para a aplicação desta tecnologia em nível de rebanho comercial.

\section{FATORES INERENTES À RAÇA}

Expulsão de larvas de $H$. contortus em ovinos pode ser imediata ou tardia. A expulsão imediata ocorre quando as larvas são atacadas pelos mastócitos do tecido e um tipo especial de mastócitos intra-epitelial (leucócitos globulares) que agem antes das larvas entrarem no seu nicho (glândula abomasal). Outros mecanismos importantes na expulsão imediata são a hiper-motilidade, hipersecreção gástrica, e hiperplasia das células calciformes e com subsequente aumento da produção de muco. Esses mecanismos podem explicar por que algumas raças de ovinos ou geneticamente resistentes neutralizam a infecção durante o início das suas fases (Alba-Hurtado e Muñoz-Guzmán, 2013).

Essa habilidade de os ovinos adquirirem e expressarem imunidade frente à ação de nematódeos gastrintestinais é controlada geneticamente e varia substancialmente entre as diferentes raças, bem como entre os indivíduos de uma mesma raça (Stear e Murray, 1994). Segundo Amarante (2009), os primórdios ovinos evoluíram não apenas como resultado da seleção natural imposta pelas condições ambientais, mas também como resultado dos processos de seleção realizados pelo homem. Em países com clima temperado, os principais nematódeos parasitas de ovinos são Ostertagia circumcincta e Teladorsagia circumcincta, enquanto em climas tropicais, destaca-se H. contortus (Bishop e Stear, 1999; Amarante et al., 2004; Benavides, 2008). Portanto, as raças europeias introduzidas no Brasil apresentam grande susceptibilidade às infecções causadas por parasitas que ocorrem nos trópicos, como é o caso de $H$. contortus (Amarante, 2009).

Amarante et al. (2004), observaram em cordeiros Santa Inês e Suffolk, mantidos sob as mesmas condições de manejo até 12-14 meses de idade, que aproximadamente, $70 \%$ dos animais Santa Inês mostraram-se resistentes às infecções por nematódeos gastrintestinais, enquanto aproximadamente $80 \%$ dos Suffolk se mostraram susceptíveis. De modo semelhante, Rocha et al. (2005), caracterizaram cordeiros Santa Inês antes 
da desmama, como mais resistentes às infecções naturais por nematódeos gastrintestinais do que cordeiros Ile de France. Em ovinos de raças resistentes, o desenvolvimento da imunidade contra os nematódeos gastrintestinais se manifesta precocemente (Amarante, 2009). Porém, estas raças consideradas resistentes apresentam algumas características relacionadas à produção consideradas inferiores (Benavides, 2008).

Mesmo as raças que apresentam alta produtividade e que são consideradas susceptíveis, apresentam variabilidade genética em relação à resposta imunológica contra os parasitas (Amarante, 2004). Porém, a diferença entre raças não tem tido grande utilização em programas de cruzamento, pelo fato de que raças resistentes não atingiriam os mesmos níveis produtivos que aquelas especializadas (Benavides, 2009). Conforme o mesmo autor há uma baixa variação de resistência dentro de linhagens ovinas, com isso é possível melhorar essa característica a parasitas gastrointestinais pela seleção em rebanhos que possuem essa variabilidade, aliando características produtivas e de resistência.

MacKinnon et al. (2009) descobriram que raças de ovinos resistentes e suscetíveis apresentaram diferentes expressões de genes quais eram associados com uma resposta a não especifica a $H$. contortus. Aos três primeiros dias de infecção ovelhas resistentes tinham reduzido à expressão de genes associados com a coagulação sanguínea e, apresentaram maior expressão de genes envolvidos na inibição de coagulantes, reparação tecidual e de reestruturação, formação de vasos sanguíneos, e a migração de células no abomaso e linfonodo abomasal. Após 27 dias de infecção, ovelhas resistentes apresentaram maior expressão dos genes associados com a motilidade intestinal, resposta imunológica, diferenciação e proliferação celular, e a redução da apoptose.

\section{FATORES INERENTES À IDADE, NUTRIÇÃO E FISIOLOGIA OVINA}

Em um rebanho ovino $100 \%$ dos animais podem ser considerados susceptíveis nas primeiras semanas de vida, porém à medida que vão crescendo e amadurecendo poderão desenvolver imunidade de tal forma que na idade adulta muitos deles poderão apresentar resistência (Amarante, 2004). Entretanto há evidências que, mesmo nos primeiros dias de vida, os animais são capazes de apresentar resposta imunológica frente aos parasitas. Emery et al. (2000), relatam que em cordeiros da raça Merino Australiano infectados por Trichostrongylus columbriformis, no período neonatal, produziram interleucina 5 (IL-5) nos linfócitos mesentéricos e de IgG. Já a infecção por $H$. contortus, em ovinos logo após o nascimento, induzi-os a responder melhor com consecutiva redução da carga parasitária após desafio com larvas. Douch e Moru (1993) encontraram maiores respostas dos mastócitos e leucócitos na mucosa gastrointestinal de animais adultos que animais jovens da raça Romney Marsh, criados ate suas respectivas idade de primeiro desafio (4 meses nos jovens e 16 e 28 meses nos adultos).

O aporte nutricional é outro fator a se considerar, onde Coop e Kyriazakis (2001) e Amarante (2009) trataram esse ponto como grande influenciador na relação parasita e parasitado (hospedeiro), quando que em primeira instância animais que recebem uma alimentação nutricionalmente adequada podem apresentar aumento da habilidade de defesa frente à ação adversa do parasitismo. Logo, aumentando a resistência, limitando o estabelecimento de larvas infectantes, o desenvolvimento e a fecundidade, ou até mesmo ocorrendo à eliminação destes nematoides já estabelecidos. Em comparação com animais isentos de infecção nematódea, ovinos que acometidos exigem maiores quantidades de proteína metabolizável para reparação de tecidos lesados, bem como para aportar nutrientes para o sistema imunológico (Amarante, 2009). Assim Kyriazakis e Houdijk (2006), estimaram que as necessidades de proteína metabolizável de cordeiros em fase de crescimento e de ovelhas em período fisiológico gestacional aumentem entre 20 a $25 \%$ quando expostos ao ambiente de alta infestação.

Houdijk et al. (2000), na Escócia, trabalhando com animais alimentados com dietas isoenergéticas, formulada para atendem 85 e $130 \%$ da exigência de proteína metabolizável, encontraram que os suplementados com maiores níveis proteicos expressaram ação imunitária contra T. circumcincta. Houdijk et al. (2001a) relatam que a magnitude da resposta frente a suplementação proteica, é maior em ovelhas que têm menores quantidades de reservas corporais deste nutriente.

A composição da dieta é outro fator de grande impacto, por exemplo, alimentos ricos em taninos condensados, quais têm ação antiparasitária agem diretamente na população helmíntica estabelecida no hospedeiro (Coop e Kyriazakis, 2001).

Alguns minerais apresentam efeito direto contra aos parasitos, Fausto et al. (2014) obtiveram que ovinos suplementados com cobre e selênio aumentaram as concentrações plasmáticas de proteínas totais e de gama albuminas, e diminuíram a carga parasitária, tomada pela redução das contagens de OPG.

Conforme Amarante (2004) os períodos de transição fisiológica são as fases que ocorre grande susceptibilidade à verminose, onde ovelhas gestantes e em lactação apresentam maior depressão imunológica ao combate de parasitas, quando comparadas ovelhas vazias e solteiras. As ovelhas têm uma grande exigência nutricional de proteína metabolizável no terço final de gestação e no inicio da lactação, em que essa exigência normalmente não é atendida, devido ao fato do seu consumo insuficiente na dieta (Coop e Kyriazakis, 2001). Os efeitos da suplementação proteica são melhores e mais pronunciados em ovelhas com gestação gemelar do que em ovelhas com um único cordeiro (Houdijk et al., 2001b).

Vários fatores têm sido observados nos animais como causadores da imunossupressão durante o período do peri-parto, dos quais Soulsby (1987) enquadra hormônios glicocorticoides, adrenocorticotróficos e a prolactina como causadores da supressão da reatividade dos linfócitos. Além disso, observa-se que durante a lactação ocorre depressão ou retardo na hiperplasia dos mastócitos intestinais, redução no número de eosinófilos e alterações na atividade da fosfolipase B intestinal. Fêmeas no pós-parto, devido a grande sus- 
ceptibilidade, influenciam diretamente na transmissão da imunidade passiva pelo colostro (Benavides, 2009).

\section{MÉTOdOS dE AVALIAÇÕES DE RESISTÊNCIA E RESPOSTA IMUNE}

Segundo Benavides (2009), a seleção para resistência demanda a utilização de contagens de ovos por grama de fezes (OPG) em animais jovens expostos a desafio, uma vez que a resistência é expressa pelos indivíduos quando as condições ambientais são propícias aos parasitas. Sem essa exposição se torna impossível medir o nível de resistência aos parasitas. A contagem de OPG é uma característica de alta variabilidade (o coeficiente de variação para essa mensuração sem transformações logarítmicas excede os $100 \%$ ) e possui uma estimativa de herdabilidade média, contudo sua expressão está dependente da exposição dos animais aos parasitas por meio de desafios anuais. As desvantagens deste método esta na irregularidade da passagem de ovos pelo trato digestório, fazendo com que em muitas vezes as amostras de fezes não acusem nenhum ovo, quando na verdade o animal está altamente parasitado. Para evitar este inconveniente, são realizadas mais de uma amostragem e mais de uma análise de OPG por animal em cada coleta, as quais estão sujeitas as condições ambientais, pois destas depende a sobrevivência dos parasitas no pasto (Bishop e Stear, 1996).

Metodologias utilizadas pelos programas de melhoramento genético para identificar animais com esta resistência descrita por Benavides (2009), ainda estão baseadas na exposição dos animais aos parasitas quando eles ainda são jovens, usando áreas de pastejo

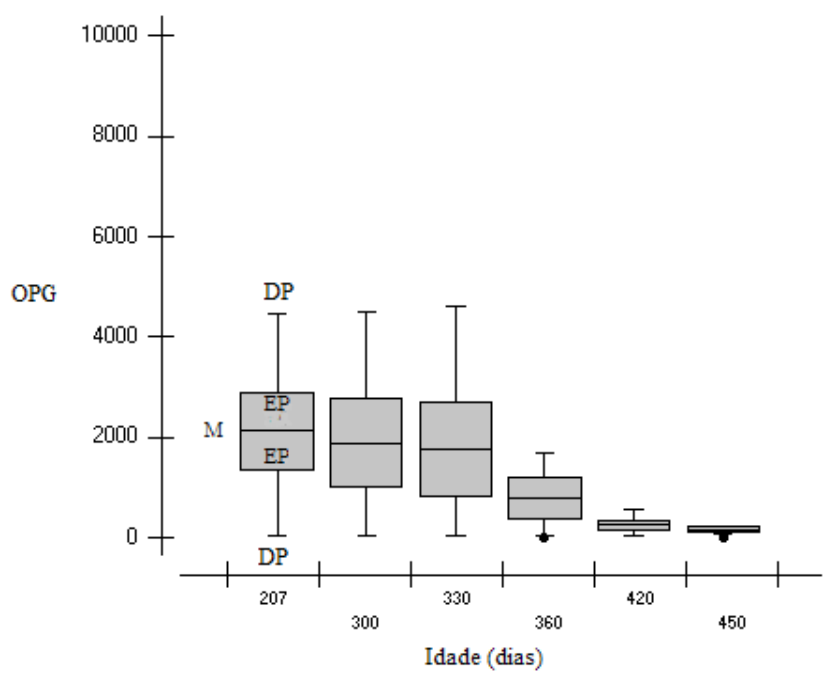

Figura 1. Médias (M), erro padrão (EP) e desvio padrão (DP) das contagens de ovos por grama de fezes (OPG) de ovinos dos 270 (pós desmame) aos 450 dias de idade (Silveira et al., 2013) (Averages (M), standard error (EP) and standard deviation (SD) of the quantification of eggs per gram of feces (FEC) of sheep of 270 (post weaning) and 450 days old).

com altas cargas parasitárias, para garantir a infecção de todos os animais. Progênies de diferentes pais são então testadas a cada ano, utilizando pais referência que possuem filhos avaliados em anos diferentes para assim poder comparar entre elas. A confiável identificação das progênies com os pais é imprescindível para a correta identificação de pais resistentes.
O método de desafio modificado por Benavides et al. (2010), consta na dosificação de todos os animais para zerar o OPG, coleta de fezes semanal em $10 \%$ do grupo, coleta de fezes individual quando média de OPG atingir 800 e nova dosificação para zerar o OPG. A fenotipagem dos ovinos quanto à sua resposta individual frente à infecção por helmintos gastrintestinais é realizada através de três ciclos sucessivos de desafio.

Outra metodologia usada para o mesmo fim é a descrita por Goldberg et al. (2011), que consta em registros genéticos obtidos a partir do desmame, com duas amostragens realizadas em ciclos parasitários independentes e baixa infecção natural. No momento do desmame (aproximadamente aos quatro meses de idade), se dosifica todos os cordeiros, e aos 10 dias afere-se novamente se a carga parasitaria encontra-se com OPG a baixo de 100. A partir desse momento, se realizam monitoramentos a cada 15 dias sobre 20 cordeiros eleitos ao acaso, até que a media aritmética supere o OPG de 500 e não mais de $20 \%$ da amostra apresente contagens menores que 100. Nesse momento, realiza-se a primeira amostragem geral (OPG1), onde se coletam amostras individuais de todos os cordeiros para análise laboratorial. Uma vez processadas as mesmas, os cordeiros novamente são dosificados, aos 10 dias são verificados, logo monitorando e quando novamente se chega ao OPG à cima de 500 se realiza a segunda amostragem geral (OPG2). Uma vez que são processadas as amostras no laboratório, os cordeiros são dosificados pela terceira vez.

Segundo Benavides (2009), apesar da técnica de OPG ser utilizada para identificar o grau de resistência dos animais, há alguns limitantes, como a condição ambiental para o desafio, ambientes adversos para à sobrevivência das formas parasitárias de vida livre podem mascarar os resultados e aumentar falsos negativos. Outro ponto é o tempo prolongado para a execução de testes de progênies e, obrigatoriamente, devem-se expor os animais jovens aos parasitas, levando-os a perder peso durante o desafio. Entretanto há uma forma alternativa de selecionar animais resistentes, que é a identificação de marcadores genéticos ligados a características de contagem de OPG (Amarante, 2004). Vários estudos nesta área estão sendo realizados na espécie ovina, com objetivo de descobrir as bases genéticas do mecanismo da resistência de indivíduos aos parasitas. Uma vez descoberto os genes responsáveis pela imunidade genética, será possível selecionar animais por meio de marcadores moleculares, e não por desafios anuais em animais jovens (Benavides, 2009).

McManus et al. (2014) em revisão descrevem um pouco sobre o complexo de maior histocompatibilidade (MHC) e a região contendo o gene do interferon gama (IFNG) sobre a resistência aos parasitas gastrintestinais. $\mathrm{O} \mathrm{MHC}$ envolve uma série de genes altamente polimórficos que são responsáveis pelo inicio da resposta imune quando um animal é desafiado por patógenos ou parasitas. Sua estrutura é relativamente bem conservada entre as diferentes espécies de ruminantes, tornando-se um candidato para estudos comparativos. O MHC é dividido em três regiões: classe 1 (telomeric), classe 2 (centromeric) e classe 3 (central). Nos ruminantes, existe uma divisão da região de clas- 
se 2 em duas sub-regiões: classe $2 a$ e $2 b$. Vários estudos demonstraram a existência de polimorfismos em cada uma delas. O MHC é localizado no cromossoma 20 em ovinos e a sua porção polimórfica é conhecida como OLA (antígeno leucocitário ovino). O MHC é associado com uma ampla gama de características de produção na pecuária. O gene que codifica para uma citosina IFNG secretada por linfócitos Th1, quais desempenham o papel crítico na regulação das respostas imunes tipo 1 vs. tipo 2 em animais vertebrados. Ela ativa macrófagos, que pode matar patógenos intracelulares, e exibem maior capacidade de resposta frente a antígenos. O INFG é usado como um candidato para resistência a nematódeos estando associado à resposta após passar por um desafio imunológico. Ele também ajuda na determinação da resposta humoral.

Woolaston et al. (1990) trabalhando com ovinos infectados artificialmente por larvas de $H$. contortus, encontraram no confronto de animais selecionados para baixo OPG, alto OPG e controle (sem seleção), após quatro gerações, que os da linha baixo OPG apresentaram infecções significativamente inferior $(p<0,001)$ quando comparada com as linhas controle e alto OPG.

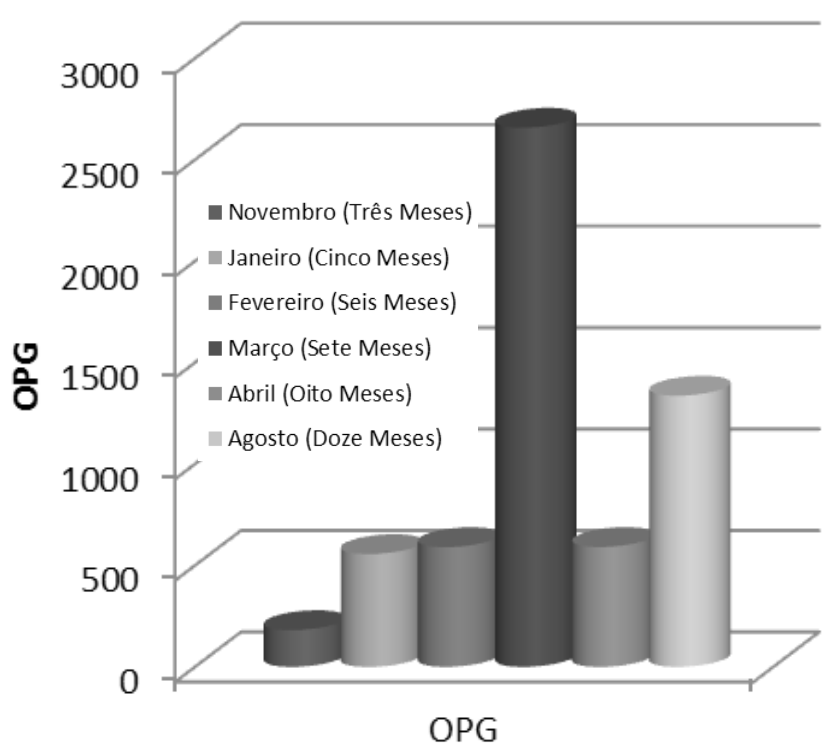

Figura 2. OPGs médios de uma população de cordeiras Corriedale desmamadas em fevereiro (Amarilho-Silveira, dados não publicados) (FECs average in a population of weaned Corriedale lambs).

O volume globular também se apresentou inversamente que os resultados de OPG, onde os animais da linha alta OPG apresentaram níveis superiores $(p<0,05)$. Esses animais em questão, também sofreram infecção artificial de T. colubriformis, e os resultados mostraram a mesma tendência observada para $H$. contortus. Stear et al. (1999) relatam que ovinos geneticamente resistentes controlavam o crescimento dos parasitas (T. circumcincta), mas não o numero deles, e ovinos com altos níveis de IgA específicos para larvas L4 de T. circumcincta apresentavam menor OPG com larvas de menor comprimento e de menor fecundidade (Stear et al., 1995; Stear et al., 1997).

O desenvolvimento da resistência contra os nematódeos tem sido associado com a resposta mediada por linfócitos Th2, o aumento do número de mastócitos na mucosa, a eosinofilia, a produção de anticorpos específicos, a presença de substância inibidoras no muco e o aumento de sua produção (Amarante e Amarante, 2003).

A ação de resistir a ação parasitária esta principalmente relacionada a uma eficiente ação imunológica mediada pelo linfócitos Th2. Qual resposta é impulsionada pelas citosinas IL4, IL5 e IL13. O perfil humoral associado à resposta dos Th2 envolve anticorpos IgA, IgG e IgE. Quais controlam a colonização larval, desenvolvimento e fecundidade do nematoide (Allen e Maizels, 2011).

Um componente importante de natureza inata também está envolvido na resposta a resistência aos nematódeos. Por exemplo, os resultados recentes sugerem que as lectinas contribuem com o aprisionamento dos nematoides numa bainha de muco, e, subsequentemente, facilita a sua eliminação. Um experimento com marcadores do tipo microssatélites comparando os níveis de expressão gênica em ovinos Martinik resistente (MBB) e Romane suscetíveis (RMN) infectados por $H$. contortus se encontrou uma indução mais forte de Th2 relacionado com citosinas e também com genes relacionados à lectina em MBB (Liénard et al., 2011).

A grelina é um peptídeo do hormônio do crescimento (28 aminoácidos) do abomaso e está ligada a secreção endógena do receptor do GH. Ela também estimula o apetite, regula a homeostase do metabolismo energético, e contribui para a modulação da resposta imunológica. Infecções experimentais com $H$. contortus em cordeiros suscetíveis reduz a expressão do gene da grelina no abomaso e diminui a proteína no plasma; em contraste, a expressão do gene da grelina e o conteúdo de proteína plasmática aumenta em cordeiros resistente. A redução da grelina é, provavelmente, associada com supressão do apetite e a regulação negativa da prolongada resposta imune em cordeiros suscetíveis (Ingham et al., 2011). Muñoz-Guzmán et al. (2012) descobriram que cordeiros resistentes, experimentalmente infectados com $H$. contortus, apresentaram respostas do tipo Th2 (aumento de eosinófilos e linfócitos T CD4 +) na região pilórica abomasal, e essa resposta não foi observada na região fúndica dos mesmos e em nenhuma região em cordeiros susceptíveis.

Rosalinski-Moraes et al. (2011), usando marcadores parasitológicos e imunológicos na seleção de ovelhas resistentes às parasitoses gastrintestinais de novembro de 1998 a maio de 1999, obtiveram o número de eosinófilos periféricos em níveis altos no mês inicial, e se manteve constante de dezembro a março. Quando que o pico de parasitismo de 30 de março foi observado redução no número de eosinófilos circulantes. Tal alteração, segundo Tizard (2009), pode ser atribuída a relação da migração para mucosa gastrintestinal induzida pela liberação de IL-5 (interleucina 5), em decorrência do estimulo parasitário. Terefe et al. (2007) documentaram a expressão de mRNA de IL-5, juntamente com IL-4 e IL-13 nos linfonodos mesentéricos de cordeiros resistentes infectados com $H$. contortus. Os níveis de IgE, se mostraram ao contrário do analisado para eosinófilos em que houve uma tendência dos 


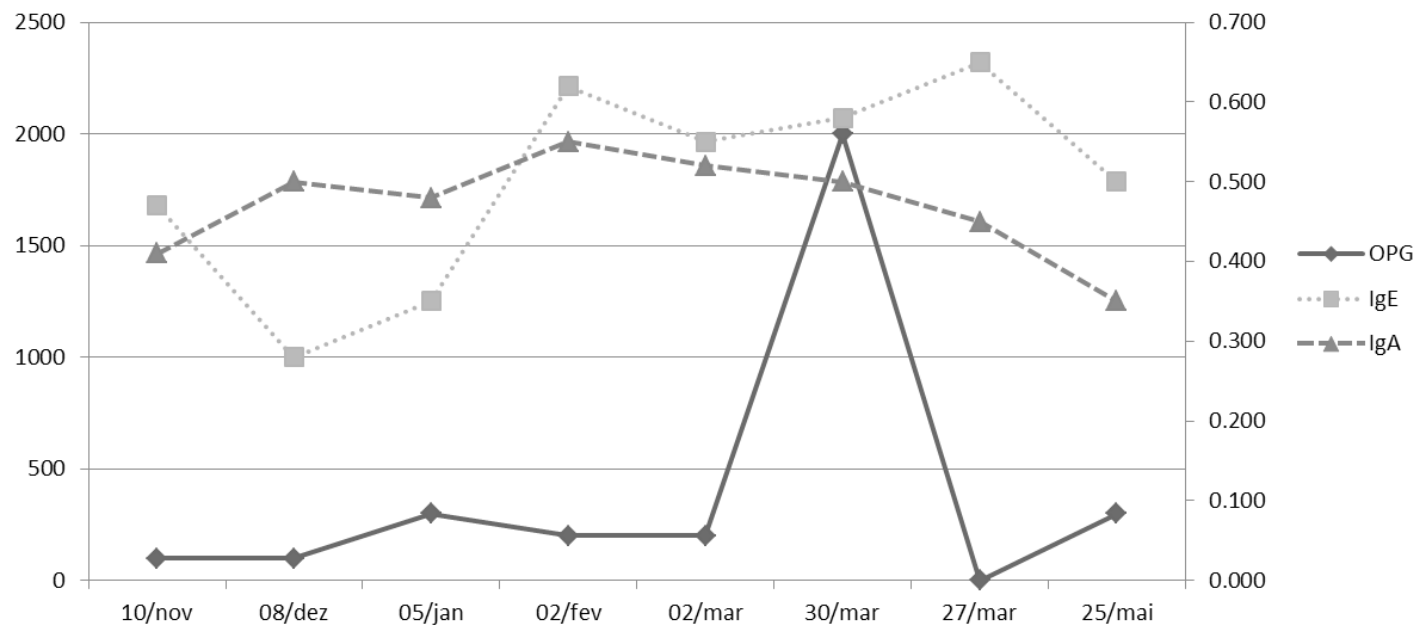

Figura 3. OPG médio mensal (linha continua, valores na vertical esquerda) e níveis mensais de $\operatorname{IgE}$ e $\operatorname{IgA}$ (linhas pontilhadas e fragmentadas, respectivamente, valores na vertical direita expressa em 492 jm) para infecção de H. contortus (adaptado de Rosalinski-Moraes et al., 2011) (Average monthly FEC (line continues, values in the left vertical) and monthly of levels IgE and IgA (dotted lines and fragmented, respectively, values in right vertical expressed in $492 \mu \mathrm{m})$ for infection of $H$. contortus)

níveis específicos desta imunoglobulina de se manter elevado durante o pico do parasitismo. Portanto, foram observados baixos valores de IgE específica nas três primeiras coletas, que pode-se atribuir a ao reflexo da transferência passiva destes anticorpos e da imunossupressão da lactação. Onde uma vez comprovada esta hipótese, a IgE específica é a ultima das variáveis imunológicas a restabelecer seus valores após o término da lactação (Rosalinski-Moraes et al., 2011). Os mesmos autores encontraram que tanto eosinófilos quanto $\operatorname{IgE}$ tendem a ser correlacionados negativamente com o OPG, entretanto, não encontraram correlações significativas com OPG e eosinófilos com IgA, qual imunoglobulina apresentou uma baixa e negativa correlação com IgE.

Segundo Balic et al. (2000), a imunidade contra os nematódeos adultos em ruminantes pode se manifestar pela expulsão da população adulta dos vermes, por alterações na morfologia dos parasitas e pela redução na fecundidade das fêmeas. Já a resistência contra os estágios imaturos dos nematódeos se manifesta pela eliminação das larvas infectantes ou pela inibição do desenvolvimento das mesmas (hipobiose) (Woolaston e Baker, 1996). Os vermes podem ser danificados diretamente pelas células efetoras e pelas moléculas do sistema imune. A interação entre o parasita e o sistema de defesa do hospedeiro pode resultar na morte e eliminação dos vermes, o que ocorre nos animais resistentes ou, no outro extremo, na persistência dos parasitas, aparentemente intactos, o que ocorre nos animais susceptíveis. Em uma situação de resistência intermediária, a infecção pode persistir, porém com prejuízos à sobrevivência e à fecundidade dos nematódeos (Amarante, 2004).

A relação entre o parasita e o seu hospedeiro leva o estabelecimento de um processo de co-evolução, onde pressões seletivas impostas por um, molda o genoma do outro ao longo do tempo. Desse modo, as mudanças nas frequências de genes que levam à fixação/perda de alelos favoráveis / desfavoráveis de ambas as populações de acolhimento e parasitas se tornam constantes e contrabalançadas, dando origem a um processo que pode ser comparado com uma corrida armamentista sem fim (Guy et al., 2012).

Neste contexto, embora a resistência e resiliência possam acarretar em um impacto semelhante na saúde individual e da produtividade, eles podem ter efeitos opostos sobre a prevalência da doença em nível de população (Doeschl-Wilson e Kyriazakis, 2012). Por exemplo, o melhoramento para resistência tem o potencial de diminuir a carga parasitária no pasto, o que proporciona benefícios epidemiológicos claros. Esta é uma previsão teórica que é importante salientar, desde infecções por nematoides são altamente prevalentes e várias espécies de nematoides têm um amplo espectro de hospedeiro (Bishop, 2012). Juntas, essas características dificultam a erradicação do patógeno, a última consequência da resistência, improvável.

Entre os mecanismos de ação do hospedeiro frente aos nematoides (expulsão da forma adulta, morte dos vermes e redução da fecundidade) a redução na fecundidade se mostra o melhor efeito para burlar a pressão de seleção dos nematoides favorecido pela ação do animal hospedeiro, ou seja, os vermes acometidos pela ação do hospedeiro com consecutiva diminuição na fecundidade, mesmo com uma mutação gênica de adaptação a essa ação, somente a fêmea é acometida. Logo se um nematoide do gênero feminino consegue superar a ação do hospedeiro, vai diluir essa característica com um macho não selecionado, assim diminuindo o progresso genético (Kemper et al., 2013). Algumas evidências obtidas por Kemper et al. (2010), onde a redução da fecundidade de vermes em ovelhas com baixo OPG, pode ser resultante da resposta imune imatura parece ser a diminuição da fecundidade do verme ao invés da diminuição do numero.

\section{USO DE MARCADORES MOLECULARES}

Em ovinos, marcadores individuais foram estimados para explicar uma máxima de $0,48 \%$ ou $0,08 \%$ da variação fenotípica para OPG após desafio com 
T. columbriformis ou $H$. contortus, respectivamente (Kemper et al., 2011).

Segundo Benavides (2009) a maioria dos marcadores moleculares possui de 2 a 15 alelos, podendo haver alguns excedendo 15, porém com menor frequência. Esses marcadores em si não controlam características de interesse, pois estão localizados em regiões que não codificam nenhuma proteína. Entretanto sua utilidade está no fato de que regiões muito próximas no cromossomo tendem a ser herdadas em blocos, e mesmo desconhecendo o(s) gene(s) responsáveis por uma determinada característica produtiva, é possível selecioná-la por meio de marcadores moleculares localizados próximos $(\sim 20 \mathrm{cM})$, uma vez que, durante o processo de recombinação, a ligação entre marcador e gene não será rompido, sendo herdado em conjunto. Esse princípio é chamado de desequilíbrio de ligação, pois, se todas as regiões de um determinado cromossomo fossem herdadas de forma independente, todas elas segregariam ao acaso (em equilíbrio). No momento que regiões são herdadas em bloco, o principio da independência não é mais válida e assim há um desequilíbrio de ligação. Por estarem amplamente difundidos nas pesquisas em todo o mundo e serem altamente polimórficos (com alta diversidade genética), o uso de marcadores moleculares do tipo microssatélites são os que possuem maior atenção. Porém há outros tipos de marcadores, como sigle nucleotide polimorphisms (SNPs), que possuem diferenças de uma a quatro bases estão sendo amplamente utilizados.

As mutações vantajosas varrem a população, juntamente com a variação relacionada, num processo referido como uma limpeza seletiva. Quando isto ocorre, esse processo deixa um rastro característico em padrões de variação em regiões genômicas ligadas ao local escolhido. Na ausência de recombinação, todos os SNPs no cromossoma neutro também se tornam fixos, perdendo, assim, toda a variabilidade na região. Novos haplótipos emergem através de recombinação, com o efeito da limpeza seletiva (desequilíbrio de ligação) diminuindo com a distância a partir do alelo vantajoso. Pressões seletivas incompletas denotam qualquer fase anterior à fixação do alelo vantajoso (McManus et al., 2014).

A identificação de marcadores conforme descrito por Benavides et al. (2002), se inicia com a formação de populações experimentalmente delineadas para tal finalidade. Um exemplo de desenho experimental é o uso de progenitores com diferença fenotípica marcante (pais resistentes com mães susceptíveis ou vice-versa) para gerar uma produção G1 segregante para esse fenótipo. Geralmente é utilizado um numero reduzido de reprodutores machos, a fim de que se obtenha um grande número de progênies de meio-irmãos G2 por pai. O estudo da resistência é realizado na população G2, em que a característica está segregando e deverá, consequentemente, apresentar uma alta variabilidade (Benavides, 2009).

Benavides (2009) descreve a existência de duas abordagens para o estudo de genes ligados a determinada característica, como a varredura total do genoma (genome wide screening) e os genes candidatos (candidate gene). A varredura total do genoma assume que os mecanismos fisiológicos que determinam o fenótipo são desconhecidos e utiliza mais de 100 marcadores moleculares distribuídos equidistantemente ao longo dos cromossomos da espécie em estudo. Por exemplo, ovinos possuem 26 pares de cromossomos autossomos e um sexual, assim já foram identificados 2.030 loci, dos quais 543 são genes, mas também possui 2.257 marcadores de microssatélites, e os SNPs descritos para ovinos ainda são poucos. Estas informações servem como ferramentas básicas para a busca de loci responsáveis, ou situados próximos a genes responsáveis, por características de interesse econômico. Os resultados significativos dos estudos de varredura total de genoma são chamados de Quantitative Trail Loci (QTLs) e indicam que dada região cromossômica, localizada entre dois marcadores testados, está significativamente ligada ao fenótipo. Uma vez localizado um QTL ligado ao fenótipo, é iniciado o processo de sintonia fina, em que é testado um maior número de marcadores moleculares situados dentro daquela região. Procura-se obter um QTL que esteja localizado entre dois marcadores moleculares mais próximos e assim sucessivamente, até chegar a uma região onde provavelmente estará o gene que explica parte ou maioria da variação fenotípica da característica que está sendo estudada. Por isso tem-se a vantagem de trabalhar com esse tipo de modelo, onde há a maior probabilidade de encontrar associações entre marcadores e características de interesse, uma vez que a busca não se restringe a poucas regiões cromossômicas.

Grasso et al. (2011) trabalhando com duas gerações de borregos Corriedale selecionados pra resistência e susceptibilidade a nematoides gastrointestinais encontraram, de um total de 54.241, somente 7 SNPs apresentaram associação com as características selecionadas, e também a análise de diploide determinou que esses marcadores tem a capacidade de indicar se um ovino é resistente ou susceptível.

A resposta imunológica é controlada por vários genes, presentes em vários loci, quais podem estarem localizados em diferentes cromossomos. A busca por marcadores genéticos QTLs em ovinos, tem sido realizada em vários países, porém com resultados muitas vezes contraditórios (Amarante, 2004). Na Austrália, Beh et al. (2002) não encontraram evidências da presença de genes principais associados com a resistência contra Trichostrongylus colubriformis em ovinos da raça Merino. Nesse estudo, marcadores localizados em algumas regiões dos cromossomos 1, 3, 6, 11 e 12 se mostraram associadas com a resistência. Em outros estudos realizados na Grã-Bretanha, foram identificados QTLs nos cromossomos 2, 3, 14 e 20 associados à resistência às infecções naturais por nematódeos gastrintestinais em ovinos Scottish Blackface (Davies et al., 2006). Na Nova Zelândia, identificou-se um QTL localizado no cromossomo 8 associado à resistência contra infecções por Trichostrongylus spp. (Crawford et al., 2006). A região 16 está contida dentro de dois QTL sugestivo detectado no cromossomo 25 em uma varredura do genoma para resistência ao $H$. contortus em cordeiros oriundos de retrocuzamento de Romane $x$ Martinik Black Belly (Sallé et al., 2012). Portanto, as di- 
ferenças observadas nos diversos estudos indicam que o controle genético da resposta imunológica é bastante complexo, e que pode variar em função da espécie do parasita que está sendo estudada (Amarante, 2004).

Kemper et al. (2013), descreveram que uma das limitações dos modelos propostos é que foi feito o estudo em um só lócus, assim há evidência que a característica de diminuição da OPG é extremamente poligênica (Kemper et al., 2011). Assim pode-se esperar que a presença de múltiplos loci afetando a eliminação de ovos nas fezes reduziria a pressão de seleção dos nematoides (Kemper et al., 2013).

Sallé et al. (2012) encontraram cinco QTL de maior interesse em OAR5, 7, 12, 13 e 21 que afetou o OPG e outros parâmetros medidos em 1000 cordeiros oriundo do retro cruzamento entre Martinik Black-Belly $\times$ Romane, para resistência a $H$. contortus.

Outra abordagem, descrita por Benavides (2009), chamada de gene candidato, onde é utilizado marcadores em regiões genômicas onde estão localizados genes importantes na fisiologia da característica a ser estudada. Considera-se esta mais racional do que a varredura genômica, no entanto ela somente é valida quando o mecanismo que determina a característica é perfeitamente conhecido. Entretanto, mesmo sabendo que proteínas alteram determinado fenótipo, é necessário um profundo estudo dos polimorfismos do(s) gene(s) em questão. Genes são compostos por várias regiões codificantes (exons) e várias não codificantes (introns), portanto o estudo de genes candidatos deve ser realizado em todos os polimorfismos descritos para determinado gene, com a finalidade de descartar um gene como não sendo ligado ao fenótipo.

Benavides et al. (2002), verificaram associações entre alelos dos marcadores CSRD2138, TGLA176 e OarAE129 (do OAR5) e OPG em dois rebanhos comerciais (das raças ovinas Corriedale e Ideal) que sofreram desafio natural, sendo $H$. contortus o parasita predominantemente. $\mathrm{O}$ alelo que apresentou maior efeito foi o CSRD2138*A que correspondeu a reduções de $28 \%$ e $22 \%$ no OPG (escala não transformada para logaritmo).

McRae et al. (2014) encontraram quatro regiões, quais continham genes que têm sido associados ou implicam para resistência ou susceptibilidade aos nematoides gastrointestinais; OAR 1 (CD53, CHI3L2, CHIA e DENND2D), OAR 4 (RELN), OAR 16 (NSUN2) e OAR 19 (HRH1). Os mesmo autores descrevem quatro regiões contendo genes que têm sido previamente implicados ou são candidatos para resistência ou susceptibilidade aos nematoides gastrintestinais. A primeira região, no cromossomo 1 (região 2), contêm antígenos de leucócitos de superfície CD53, bem como DENND2D e três genes da família quitinase, acidic mammalian chitinase (CHIA), chitinase 3-like 2 (CHI3L2) e glicoproteína oviduct-specific (OVGP1). A reposta a seleção também foi observado no cromossomo 4 (região 5), cromossomo 16 (região 14) e cromossomo 19 (região 15), que contém genes previamente implicados na resistência a nematoides gastrointestinais. Lee et al. (2011), associou previamente o CHIA com o controle de infecções helmínticas.
A proteína DENND2D foi encontrada em maior abundância em ovelhas geneticamente susceptíveis a seguir por infecção de H. contortus (Nagaraj et al., 2012). RELN foi regulada em ovinos Suffolk susceptíveis em comparação com Texel resistentes, animais pós três dias de infecção por T. circuncta (Ahmed, 2013).

Usando single-marker tests para diferenciação entre linha de seleção, foram descobertas em várias regiões onde a frequência alélica diferiu entre animais resistentes e susceptíveis (McRae et al., 2014). Em que isso era esperado, como uma variação de traços complexos, tais como resistência a parasitas são controladas por diversos polimorfismos de pequeno efeito (Kemper et al., 2011). O modelo clássico de varredura envolve um alelo a ser conduzido rapidamente para fixação (hard sweep). No entanto, com características complexas pode ocorrer seleção através da adaptação poligênica, onde a adaptação ocorre através da seleção simultânea de variantes em muitos loci. $\mathrm{O}$ modelo de seleção com adaptação poligênica resultaria em mudanças modestas de frequências alélicas em todo o genoma, o que pode ser indetectável utilizando os métodos atuais pra esse fim (Protchard et al., 2010). Apesar de isso a hard sweep e os modelos poligênicos não são mutuamente exclusivos, e os alelos com maior efeito podem varrer a fixação (Protchard e Di Rienzo, 2010).

O gene mais próximo, encontrado, na região subjacente a 4-SNP foi o gene da PAPP-A2. O gene codifica uma protease de clivagem Insulin Growth Factor Binding Protein-4 (IGFBP4), qual aumenta a biodisponibilidade da o fator de crescimento semelhante à insulina (IGF). O gene de IGF desempenha um papel importante na resposta imune (Conover, 2012) e foi recentemente associada à resposta Th2 induzida por nematódeos (Chen et al., 2012). Além disso, a expressão de PAPP-A2 é altamente dependente de citosinas préinflamatórias, tais como IFN-y e TNF $\alpha$ e são induzidas durante a cicatrização de feridas causadas pela ação parasitária (Conover, 2012).

Segundo Bishop e Morris (2007), há uma grande variação na resposta de OPG em relação a polimorfismos genéticos em diferentes genes e regiões cromossômicas. Portanto, é provável que a seleção assistida por marcadores para resistência a parasitas gastrintestinais em ruminantes seja determinada por vários genes, e não por um gene principal. $O$ fato de a resistência estar ligada a vários genes pode ter desdobramentos práticos. A possibilidade de evasão dos parasitas para os mecanismos imunes, pelas mutações no genoma desses organismos, é a maior crítica que a seleção assistida recebe.

\section{ASPECTOS RELACIONADOS AO MELHORAMENTO GENÉTICO}

As estimativas dos coeficientes de herdabilidade da resistência dos ovinos aos helmintos são moderados com valores similares, em magnitude, aos da herdabilidade de caracteres de produção, tais como, ganho de peso e produção de lã, características para as quais a seleção tem sido um sucesso (BARGER, 1989). Segundo Amarante (2004) os coeficientes de herdabilidades variam de 0,3 a 0,5 . 
Kemper et al. (2011) descobriram que existem muitos polimorfismos de pequeno efeito subjacente na variação do OPG. Assim os mesmos autores encontraram que os maiores efeitos foram estimados para explicar entre 0,12 e 0,48\% da variação fenotípica para o seguinte OPG do desafio com T. colubriformis, e entre 0,02 e $0,08 \%$ da variação fenotípica do seguinte OPG do desafio $H$. contortus. Os efeitos genéticos aditivos para o OPG foi responsável de 10 a $24 \%$ da variação fenotípica nesta população, isto significa que há uma probabilidade de haver centenas ou milhares de mutações subjacentes que influenciam estes fenótipos. Estas mutações provavelmente estão espalhadas por todo o genoma.

McManus et al. (2013) em um estudo com várias raças e cruzamentos, descobriram que raças localmente adaptadas como Morada Nova e Bergamasca (na região central do Brasil) mostraram baixa OPG para Strongylideos, enquanto raças localmente adaptados como Santa Inês e suas cruzas com Ile de France (IlexSI) apresentaram os menores valores de OPG para Strongyloides. Por outro lado, a menor quantificação de oocistos nas fezes (FOC - Eimeria spp.) foi encontrado em ovelhas Ile de France. As correlações genéticas entre a OPG ou FOC e as respectivas espécies de parasitas em estas ovelhas eram baixas, e de herdabilidade que variaram de 0,09 para 0,31.

Woolaston et al. (1992) em experimento com duas linhagens de ovinos Merino, resistentes e susceptíveis à hemoncose, obtiveram resultados quais mostraram que o parasita $H$. contortus, não apresentou qualquer alteração após 14 gerações. Logo mostrando que não houve nenhum tipo de modificação à adaptação deste parasita a resposta imunológica do hospedeiro. Juntamente a isso, ao selecionar animais para resistência a o $H$. contortus, indiretamente, será selecionado animais resistentes também a o T. colubriformis (Sréter et al., 1994). Provavelmente, esse fato seja devido falta de evidências relacionadas à adaptabilidade para cada caso de aversão endógena de ovinos com resistência a diferentes espécies de nematoides (Amarante, 2004).

A resistência do hospedeiro é uma característica hereditária, com grande variabilidade entre indivíduos, onde com simulações usando modelos computacionais se mostra que a seleção para hospedeiros resistentes, utilizando como carácter fenótipo baixa eliminação de ovos nas fezes, provavelmente se estabilize em um curto período de tempo, cerca de 20 anos de seleção (Kemper et al., 2013).

Não há evidências da adaptação dos nematoides frente ovinos resistentes a suas infecções, logo devese, pela hipótese, de que a resistência é determinada por muitos genes cada um com efeito relativamente pequeno, sendo a seleção por OPG uma ferramenta sustentável a médio e longo prazo (Kemper et al., 2011).

A menor contagem, provavelmente, é devido a menor capacidade reprodutiva dos nematoides no hospedeiro. A maior preocupação é a adaptação dos nematoides frente à ação do hospedeiro selecionado para baixo OPG. A expectativa é que resultados de seleção natural dos nematoides pode aumentar sua aptidão, ou seja, sua capacidade reprodutiva ao longo do tempo pode promover os benefícios de selecionar ovinos para baixo OPG (Kemper et al., 2013). Stear (2010) explica que a possível razão da não evolução adaptativa dos nematoides frente à ação de resistência do hospedeiro, é dada visto que animais resistentes eliminam menos ovos nas fezes, assim a maior população de nematoides no ambiente é oriunda de animais susceptíveis.

Os vermes frente às ações do hospedeiro, de resistência, se adaptam e ficam mais susceptíveis ao ambiente. Assim quando há um aumento da frequência de alelos para resistência no ovino, em contrapartida há um aumento na pressão de seleção dos vermes para suportar a ação do hospedeiro (Kemper et al., 2013).

A natureza poligênica da resistência ovina sugere que a evolução parasitária frente à reatividade do hospedeiro deve ser de progresso mais lento do que de resistência anti-helmíntica, para tal os nematódeos teriam de evoluir contra muitos mais alvos (Bishop, 2012).

Sallé et al. (2012) trabalhando com cordeiros oriundo do retro cruzamento entre Martinik Black-Bellyx Romane, não encontraram diferença no numero de vermes encontrado no interior do abomaso e na taxa de crescimento corporais entre cordeiros portadores de alelos relacionados com a resistência submetidos a infecção de $H$. contortus (Ri) quando comparado a animais que apresentavam alelos com influencia neutra submetido a mesma infecção $(\mathrm{Ni})$ a resistência a infecção a $H$. contortus. Os grupos com genótipos com base no haplótipo genótipo 4-SNP mostrou redução significativa no OPG (600 para $R$ e 11.000 para N), queda no hematócrito e na fecundidade dos parasitas (1,5 vezes menos ovos no útero de fêmeas $H$. contortus nos ovinos do grupo R). Animais Ri apresentaram um aumento de quatro vezes na expressão dos genes IL-4 e IL-13 da mucosa abomasal quando comparado aos Ni. Foi notada uma citosina de carácter mais forte de Th2 nos animais Ri, também foi reforçado por uma significativa redução de $1 / 3$ da expressão do fator IFN-y na mucosa abomasal entre animais Ri e animais portadores deste alelo, mas sem serem submetidos à infecção $(\mathrm{Ru})$, qual não pode ser encontrado nos animais $\mathrm{Ni}$ e animais portadores deste alelo, mas sem serem submetidos à infecção $(\mathrm{Nu})$.

Raramente programas de seleção consideram o baixo OPG como única característica a ser selecionada, por isso as estimativas de correlações genéticas entre OPG e características produtivas são importantes (Benavides et al., 2010). Esses autores obtiveram em estudo com animais da raça Merino Australiano correlações negativas com peso ao nascer e peso ao desmame, o que significa que ovinos mais resistentes (baixo OPG) tenderam a ter maiores pesos. No caso das características de produção de lã (pesos de velo sujo e limpo, diâmetro médio de fibra e comprimento de mechas), a seleção de ovinos mais resistentes não acarretaria em perdas na produção de lã uma vez que as correlações entre estas características são de baixa magnitude.

A seleção direta, onde as herdabilidade são geralmente média a baixa, traz resultados lentos a seleção para esses traços, assim os valores econômicos tendem, 
também, a serem baixos, mas são altamente afetadas pelo preço de diagnostico e tratamento (Lôbo et al., 2011).

Há poucos estudos que se detém a estudar o valor econômico da implementação de genes favoráveis a resistência a parasitas gastrointestinais (FAO, 1999). Na mesma citação defende-se um número de vantagens em incorporar elementos genéticos com intuito de facilitar estratégias de gestão, como a permanência da mudança genética, uma vez que está estabelecida; a coerência do efeito; a ausência da necessidade de insumos comprados uma vez que o efeito é estabelecido; a eficácia de outros métodos é prolongada como existe menos pressão para o surgimento de resistência; possibilidade de efeitos de amplo espectro (aumentando resistência a mais do que uma doença); possibilidade de ter menor impacto sobre a evolução de macroparasitas como helmintos, em comparação com outras estratégias, como a quimioterapia ou vacinação; e a adição à diversidade do homem-doença de estratégias de gestão.

Dependendo da natureza do problema e os recursos de gestão disponíveis, a nível genético uma doença pode ter seu efeito reduzido tomado por medida algumas maneiras. Estes incluem seleção de raça adequada para o ambiente de produção; cruzamentos para introduzir genes desejáveis em raças que são de outro modo bem adaptadas; e a seleção de indivíduos que tendem a resistência ou a tolerância. A diversidade genética é uma exigência fundamental em todos os casos e as populações que são diversas em termos de números de genótipos diferentes conferindo resistência à doença são menos suscetíveis a catastróficas epidemias (Springbett et al., 2003).

Devido a mudanças ambientais esperadas em consequência do aquecimento global, a seleção de genótipos adaptados ao meio será importante para assegurar um aumento sustentável da produção. Isso também será importante para definir objetivos e desenvolver critérios de seleção que garantam que a criação de animais é eficaz e que visa à produção sustentável conforme as mudanças de ambientes. Objetivos e critérios de definição reprodutiva estão comumente em falta nos programas de melhoramento, especialmente nos países em desenvolvimento, onde o impacto da mudança ambiental deverá ser superior. Sistemas ótimos de produção são aqueles que estão em harmonia com o meio ambiente e utilizam genótipos adequados, e que devem ser desenvolvidos, onde já estejam adaptados. Durante o desenvolvimento destes sistemas, fatores de melhoramento devem ser considerados e ligados a fatores de sustentabilidade dos sistemas de produção relacionados a mudanças ambientais (Scholtz et al., 2013).

\section{CONSIDERACOÕES FINAIS}

A eleição de uma raça não deve considerar somente fatores de produção que estão relacionados diretamente no desempenho, e sim o custo/beneficio de buscar raças de menor especialização, porém com menor susceptibilidade frente aos parasitos, qual resistência pode surtir numa menor mobilização de recursos financeiros para futuros tratamentos, e suplementações estratégicas para recuperar ganhos almejados que não foram alcançados.

Considerar alguns aspectos como idade, transições fisiológicas e status nutricional pode diminuir a demanda por tratamentos químicos, tanto em animais resistentes e principalmente em susceptíveis. Pois nada vale o empenho da herança gênica se as condições para produzir não são mínimas compatíveis. Logo sabendo que mesmo animais selecionados e acasalados para fixação da característica de resistência a parasitos gastrointestinais, quando em ambiente próximo a saturação parasitária, se encontram a mercê da susceptibilidade de demandas fisiológicas e que se não supridas podem inibir essa característica de lento progresso genético.

Lançar mão do uso de ferramentas para fenotipagem de animais que se apresentam no patamar da resistência a nematoides gastrointestinais é de suma importância para o progresso dessa característica. Logo se faz necessário o conhecimento das ações imunológicas que interagem, quando uma vez desafiados.

$\mathrm{O}$ uso de marcadores e da identificação de genes que capacitam o entendimento da sua resposta, à parte dessa manifestação imunológica, diminuiu a demanda de tempo de fenotipagem, logo assim tornando o processo mais objetivo, porém com custo mais elevado.

Uma vez, com todas as ferramentas do conhecimento da ação imunológica, fisiológica e de como fenotipalas, tem-se que tratar de colocar em prática, assim adaptando a cada realidade os carácteres necessários para a obtenção de algum ou maior progresso genético para resistência frente a parasitos gastrointestinais, logo sempre ponderando o custo/beneficio dentro de cada sistema de produção.

\section{BIBLIOGRAFIA}

Ahmed, A.M. 2013. Immunological and transcriptomic analysis of genetically resistant and susceptible sheep to gastrointestinal nematodes. PhD Thesis. University College. Dublin.

Alba-Hurtado, F. and Muñoz-Guzmán, M.A. 2013. Immune responses associated with resistance to Haemonchosis in sheep. BioMed Res Int, 2013: 1-11.

Allen, J.E. and Maizels, R.M. 2011 . Diversity and dialogue in immunity to helminths. Nat Rev Immunol, 11: 375-388.

Almeida, M.A.; Botura, M.B.; Santos, M.M.; Almeida, G.N.; Domingues, L.F.; Costa, S.L. e Batatinha, M.J.M. 2003. Efeitos dos estratos aquosos de folhas de Cymbopogon citratus (D.C.) Stapf (Capim-santo) e de Digitaria insularis (L.) Fedde (Capim-açu) sobre cultivos de larvas de nematóides gastrintestinais de caprinos. Rev Bras Parasitol Vet, 12: 125-129.

Amarante, A.F.T. and Amarante, M.R.V. 2003. Breeding sheep for resistance to 8 nematode infections. J Anim Vet $A d v$, 2: 147-161. 
Amarante, A.F.T.; Bricarello, P.A.; Rocha, R.A. and Gennari, S.M. 2004. Resistance of Santa Ines, Suffolk and lle de France lambs to naturally acquired gastrointestinal nematode infections. Vet Parasitol, 120: 91-106.

Amarante, A.F.T. 2009. Nematoides gastrintestinais em ovinos. In: Cavalcante, A.C.R.; Vieira, L.S.; Chagas, A.C.S. e Molento, M.B. (Eds). Doenças parasitárias de caprinos e ovinos: epidemiologia e controle. Embrapa Informação Tecnológica. Brasília, DF. pp. 17-62.

Amarante, A.F.T. 2004. Resistência genética a helmintos gastrointestinais. In: Simpósio da Sociedade Brasileira de Melhoramento Animal, Pirassununga. Anais... Simpósio da Sociedade Brasileira de Melhoramento Animal, São Paulo. pp. 1-5.

Balic, A.; Bowles, V.M. and Meeusen, E.N.T. 2000. The immunobiology of gastrointestinal nematode infections in ruminants. Adv Parasitol, 45: 181-241.

Barbosa, C.M.P.; Rodrigues, L.T.; Cury, I.T.S.; Curci, V.C.L.M. e Cardoso, D. 2013. Teste de eficácia de anti-helmínticos em caprinos em uma propriedade de Araçatuba, Estado de São Paulo. In: XXIII Congresso Brasileiro de Zootecnia, Foz Do Iguaçu. Anais Universidade Federal do Oeste do Paraná. Foz do Iguaçu. Paraná, 23.

Barger, I.A. 1989. Genetic resistance of hosts and its influence on epidemiology. Vet Parasitol, 32: 21-35.

Beh, K.J.; Hulme, D.J.; Callaghan, M.J.; Leish, Z.; Lenane, I.; Windon, R.G. and Maddox, J.F. 2002. A genome scan for quantitative trait loci affecting resistance to Trichostrongylus colubriformis in sheep. Anim Genet, 33: 97-106.

Benavides, M.V.; Weimer, T.A.; Borb, M.F.S.; Berne, M.F.A. and Sacco, A. M.S. 2002. Association between microsatellite marks of sheep chromosome 5 and faecal egg counts. Small RuminantRes, 46: 95-105.

Benavides, M.V. 2008. Prós e contra da resistência genética dos ovinos aos helmintos gastrintestinais. Documentos EMBRAPA, 79. Bagé. Rio Grande do Sul.

Benavides, M.V. 2009. Marcadores moleculares para resistência. In: Cavalcante, A.C.R.; Vieira, L.S.; Chagas, A.C.S. e Molento, M.B. (Eds.). Doenças parasitárias de caprinos e ovinos: epidemiologia e controle. Brasília, DF. Embrapa Informação Tecnológica, 508-548.

Benavides, M.V.; Souza, C.J.H.; Moraes, J.C.F.; Berne, M.F.A. e Ledur, M.C. 2010. Resistência a parasitos gastrintestinais de ovinos Merino Australiano no RS e suas correlações com características produtivas. In: XI Simpósio Iberoamericano Sobre Conservación y Utilización de Recursos Zoogenéticos. João Pessoa.

Bishop, S.C. and Morris, C.A. 2007. Genetics of disease resistance in sheep and goats. Small Ruminant Res, 70: 48-59.

Bishop, S.C. and Stear, M.J. 1999. Genetic and epidemiological relationships between productivity and disease resistance: gastro-intestinal parasite infection in growing lambs. Anim Sci, 69: 51 5-524.

Bishop, S.C. 2012. Possibilities to breed for resistance to nematode parasite infections in small ruminants in tropical production systems. Anim. Sci, 6: 741-747.

Conover, C.A. 2012. Key questions and answers about pregnancyassociated plasma protein-A. Trends Endocrinol Metab, 23: 242-249.

Coop, R.L. e Kyriazakis, I. 2001. Influence of host nutrition on the desevolpment and consequences of nematode parasitsm in ruminants. Trends Parasitol, 17: 325-330.

Cordeiro, R.C. 2008. Aplicabilidade do uso do fungo nematófago Duddingtonia flagrans no controle de nematóides gastrintestinais de ovinos no Norte Fluminense. J Bras Ciênc Anim, 1.

Crawford, A.M.; Paterson, K.A.; Dodds, K.G.; Tascon, C.D.; Williamson, P.A.; Thomson, M.R.; Bisset, S.A.; Beattie, A.E.; Greer, G.J.;Green, R.S.; Wheeler, R.; Shaw, R.J.; Knowler, K. and McEwan, J.C. 2006. Discovery of quantitative trait loci for resistance to parasitic nematode infection in sheep: I. Analysis of outcross pedigrees. BMC Genomics, 7: 178. http://www.biomedcentral.com/1471-2164/7/178(12/03/2014).

Davies, G.; Stear, M.J.; Benothman, M.; Abuagob, O.; Kerr, A.; Mitchell, S. and Bishop, S.C. 2006. Quantitative trait loci associated with parasitic infection in Scottish blackface sheep. Heredity, 96: 252-258.
Doeschl-Wilson, A.B. and Kyriazakis, I. 2012. Should we aim for genetic improvement in host resistance or tolerance to infectious pathogens? Front Genet, 3: 1-2.

Douch, P.G.C. and Moru, P.E. 1993. The effect of age on the response of Romney sheep to gastrointestinal nematodes duting grazing. Int $J$ Parasitol, 23: 65. 651-655.

Emery, D.L.; McClure, S.J. and Devey, R.J. 2000. Protection of Merno lambs against Haemonchus contortus by trickle infection of neonates. Parasitol Int, 49: 165-170.

FAO. 1999. Opportunities for incorporating genetic elements into the management of farm animal diseases: policy issues. In Background Study Paper Number 18. Commission on Genetic Resources for Food and Agriculture. Bishop, S.; De Jong, M. and Gray, D. (Eds.). FAOSTAT. Rome. http://faostat.fao.org (26/02/2015).

Fausto, G.C.; Pivoto, F.L.; Costa, M.M.; Lopes, S.T.A.; França, R.T.; Molento, M.B.; Minervino, A.H.H.; Rocha, J.B.T. and Leal, M.L.R. 2014. Protein profile of lambs experimentally infected with Haemonchus contortus and supplemented with selenium and copper. Parasites \& Vectors, 7: 355. http://www.parasitesandvectors.com/content/7/1/355 (26/02/2015).

Goldberg, V.; Ciappesoni, G.; Barbieri, I.; Rodríguez, A. y Montossi, F. 2011 . Factores no genéticos que afectan la resistencia a parásitos gastrointestinales en merino en Uruguay. Producción Ovina. Canelones, 21:1-11.

Grasso, N.; Iriarte, W. and Ciappesoni, G. 2011. High throughput genotyping of nematode resistant/susceptible Corriedale sheep. $34^{\circ}$ Congreso Argentino de Producción Animal. $1^{\text {st }}$ Join Meeting AAPAASAS. Rev Argent Prod Anim, 1: 1-134.

Guy, S.Z.Y.; Thomson, P.C. and Hermesch, S. 2012. Selection of pigs for improved coping with health and environmental challenges: breeding for resistance or tolerance? Front Genet, 3: 1-9.

Houdijk, J.G.M.; Kyriazakis, I.; Jackson, F. and Coop, R.L. 2000. Can an increased intake of metabolizable protein affect the periparturient relaxation in immmunity aginst Teladostargia circumcincta in sheep? Vet Parasitol, 91: 43-62.

Houijk, J.G.M.; Kyriazakis, I.; Coop, R.L. and Jackson, F. 2001 a. The espression of immunity to Teladorsagia circumcincta in ewes and its relationship to protein nutrition depend on body protein reserves. Parasitology, 122: 661-672.

Houdiijik, J.G.M.; Kyriazakis, I.; Jackson, F. and Coop, R.L. 2001b. The relationship between protein nutrition, reprodutive effort and breakdown in immunity to Teladorsagia circumcincta in periparturient ewes. Anim Sci, 72: 595-606.

Ingham, A.; Menzies, M.; Hunt, P.; Reverter, A.; Windon, R. and Andronicos, N. 2011. Divergent ghrelin expression patterns in sheep genetically resistant or susceptible to gastrointestinal nematodes. Vet Parasitol, 181: 194-202.

Kemper, K.E.; Palmer, D.G.; Liu, S.M.; Greeff, J.C.; Bishop, S.C. and Karlsson, L.J.E. 2010. Reduction of faecal worm egg count, worm numbers and worm fecundity in sheep selected for worm resistance following artificial infection with Teladorsagia circumcincta and Trichostrongylus colubriformis. Vet Parasitol, 171: 238-246.

Kemper, K.E.; Emery, D.L.; Bishop, S.C.; Oddy, H.; Hayes, B.J.; Dominik, S.; Henshall, J.M. and Goddard, M.E. 2011. The distribution of SNP marker effects for faecal worm egg count in sheep, and the feasibility of using these markers to predict genetic merit for resistance to worm infections. Genet Res, 93: 203-219.

Kemper, K.E.; Goddard, M.E. and Bishop, S.C. 2013. Adaptation of gastrointestinal nematode parasites to host genotype: single locus simulation models. Genet Sel Evol, 45: 1-14. http://www.gsejournal. org/content/45/1/14 (23/02/2015).

Kyriazakis, I. and Houdijk, J. 2006. Immunonutrition; nutricional control of parasites. Small Ruminat Res, 62: 79-82.

Lee, C.G.; Da Silva, C.A.; Dela Cruz, C.S.; Ahangari, F.; Ma, B.; Kang, M-J.; He, C-H.; Takyar, S. and Elias, J.A. 2011. Role of chitin and chitinase/chitinase-like proteins in inflammation, tissue remodeling, and injury. Annu Rev Physiol, 73: 479-501. 
Liénard, E.; Foucras, G.; Prévot, F.; Grisez, C.; Bergeaud, J.P.; François, D.; Bouvier, F. and Jacquiet, P. 2011 . Comparison of gene expression profiles between resistant and susceptible ovine breeds to Haemonchus contortus. 23rd World Association for the Advancement of Veterinary Parasitology. Buenos Aires. Argentina.

Lôbo, R.N.B.; Pereira, I.D.C. and Facó, O. 2011. Economic values for production traits of Morada Nova meat sheep in a pasture based production system in semi-arid Brazil. Small Ruminant Res, 96: 93-100.

Mackinnon, K.M.; Burton, J.L.; Zajac, A.M. and Notter, D.R. 2009. Microarray analysis reveals difference in gene expression profiles of hair and wool sheep infected with Haemonchus contortus. Vet Immunol Immunop, 130: 210-220.

McManus, C.M.; Dallago, B.S.L.; Louvandini, H.; Melo, C.B.; Seixas, L.S. and Oliveira, F.J.G. 2013. Gastrointestinal parasitism in sheep kept on Andropogon and Panicum pastures in the Federal District. Brazil. J Anim Sci Adv, 3: 214-218.

McManus, C.; Paim, T.P.; Melo, C.B.; Brasil, B.S.A.F. and Paiva, S.R. 2014. Selection methods for resistance to and tolerance of helminths in livestock. Parasite, 21: 1-56

McRae, K.M.; McEwan, J.C.; Dodds, K.G. and Gemmell, N.J. 2014. Signatures of selection in sheep bred for resistance or susceptibility to gastrointestinal nematodes. BMC Genomics, 15: 637. http://www. biomedcentral.com/1471-2164/15/637 (23/02/2015).

Miller, C.M.; Waghorn, T.S.; Leathwick, D.M.; Candy, P.M.; Oliver, A.M.B. and Watson, T.G. 2012. The production cost of anthelmintic resistance in lambs. Vet Parasitol, 186: 376-381.

Molento, M.B.; Tasca, C.; Gallo, A.; Ferreira, M.; Bononi, R. and Stecca, E. 2004. Famacha guide as an individual clinic parameter for Haemonchus contortus infection in small ruminants. Cienc Rural, 34: 1139-1145.

Molento, M.B. 2009. Método Famacha no controle de Haemonchus contortus. In: Cavalcante, A.C.R.; Vieira, L.S.; Chagas, A.C.S. e Molento, M.B. (Ed(s)). Doenças parasitárias de caprinos e ovinos: epidemiologia e controle. Brasília, D.F.: Embrapa Informação Tecnológica, 367-400.

Molento, M.B.; Fortes, F.S.; Pondelek, D.A.S.; Borges, F.A.; Chagas, A.C.S.; Torres-Acosta, J.F. and Geldhof, P. 2011 . Challenges of nematode control in ruminants: focus on Latin America. Vet Parasitol, 180: 126-132.

Muñoz-Guzmán, M.A.; Cuenca-Verde, C.; Valdivia-Anda, C.; CuéllarOrdaz, J.A. and Alba-Hurtado, F. 2012. Differential imune response between fundic and pyloric abomasal regions upon experimental ovine infection with Haemonchus contortus. Vet Parasitol, 185: 175-180.

Nagaraj, S.H.; Harsha, H.C.; Reverter, A.; Colgrave, M.L.; Sharma, R.; Andronicos, N.; Hunt, P.; Menzies, M.; Lees, M.S.; Sekhar, N.R.; Pandey, A. and Ingham, A. 2012. Proteomic analysis of the abomasal mucosal response following infection by the nematode, Haemonchus contortus, in genetically resistant and susceptible sheep. J Proteomics, 75: 2141-2152.

Nunes, R.L.; Dos Santos, L.L.; Bastianetto, E.; De Oliveira, D.A.A. and Brasil, B.S.A.F. 2013. Frequency of benzimidazole resistance in Haemonchus contortus populations isolated from buffalo, goat and sheep herds. Rev Bras Parasitol Vet, 22: 548-553.

Pritchard, J.K.; Pickrell, J.K. e Coop, G. 2010. The genetics of human adaptation: hard sweeps, soft sweeps, and polygenic adaptation. Curr Biol, 20: 208-215.

Pritchard, J.K. and Di Rienzo, A. 2010. Adaptation - not by sweeps alone. Nat Ver Genet, 11: 665-667.

Rocha, R.A.; Amarante, A.F.T. and Bricarello, P.A. 2005. Resistance of Santa Inês and lle de France suckling lambs to gastrointestinal nematode infections. Rev Bras Parasitol Vet, 14: 17-20.

Roslinski-Moraes, F.; Sotomaior, C.S.; Schmidt, E.M.S. e Thomas-Soccol, V. 2011. Uso de marcadores parasitológicos e imunológicos na seleção de ovelhas resistentes às parasitoses gastrintestinais. Arch Vet Sci, 16: 7-20.

Sallé, G.; Jacquiet, P.; Gruner, L.; Cortet, J.; Sauvé, C.; Prevot, F.; Grisez, C.; Bergeaud, J.P.; Schibler, L.; Tircazes, A.; Francois, D.; Pery, C.; Bouvier, F.; Thouly, J.C.; Brunel, J.C.; Legarra, A.; Elsen, J.M.; Bouix, J.; Rupp, R. and Moreno, C.R. 2012. A genome scan for QTL affecting resistance to Haemonchus contortus in sheep. J Anim Sci, 90: 4690-4705.

Scholtz, M.M.; Maiwashe, A.; Neser, F.W.C.; Theunissen, A.; Olivier, W.J.; Mokolobate, M.C. and Hendriks, J. 2013. Livestock breeding for sustainability to mitigate global warming, with the emphasis on developing countries. S Afr J Anim Sci, 43: 269-281.

Silveira, F.A.; Ferreira, O.G.L.; Coelho, R.T.; Brondani, W.C.; Costa, O.A.D. e Esteves, R.M.G. 2013. Influência da idade na resistência à verminose de borregas cruza Lacaune. In: $28^{\circ}$ Jornada Acadêmica Integrada. Universidade Federal de Santa Maria. Apresentação, 28.

Silveira, F.A.; Ferreira, O.G.L.; Farias, P.P.; Lopes, A.G.; Oliveira, L.V.; Esteves, R.M.G.; Pinto, N.B. e Barbosa, L.R.D.A. 2013. Teste de eficiência de anti-helmínticos em ovinos sob sistema de manejo semi-extensivo. In: Congresso Brasileiro de Zootecnia, Foz do Iguaçu. Anais... Zootec, 23. Paraná. Brasil.

Soulsby, E.J.L. 1987. The evasion of immune response and immunological unresponsiveness: parasitic helminth infection. Immunol Lett, 16: 315-320.

Springbett, A.J.; Mackenzie, K. and Woolliams, J.A. 2003. The contribution of genetic diversity to the spread of infectious diseases in livestock populations. Genetics, 165: 1465-1474.

Sréter, T.; Kassay, T. and Takás, E. 1994. The heritability and specificity of responsiveness to infection with Haemonchus contortus in sheep. Int J Parasitol, 24: 871-876.

Stear, M.J. and Murray, M. 1994. Genetic resistance to parasitic disease: particularly of resistance in ruminants to gastrointestinal nematodes. Vet Parasit, 54: 161-176.

Stear, M.J.; Bairden, K.; Duncan, L.L.; Gettinby, G.; McKellar, Q.A.; Murray, M. and Wallace, D.S. 1995. The distribuition of faecal nematode egg counts in Scottish Blackface lambs following natural, predomintly Ostertagia circumcincta infection. Parasitology, 110: 573-581.

Stear, M.J.; Bairden, K.; Duncan, J.L.; Holmes, P.H.; McKellar, Q.A.; Park, M.; Strain, S.; Murray, M.; Bishop, S.C. and Gettinby, G. 1997. How hosts control worms. Nature, 389: 27.

Stear, M.J.; Strain, S. and Bishop, S.C. 1999. How lambs control infection with Ostertagia circumcincta. Vet Immunol Immunop, 72: 213-218.

Stear, M.J. 2010. Breeding for resistance to nematode infections. In: Breeding for disease resistance in farm animals. 3rd edition. Bishop S.C.; Axford, R.F.E.; Nicholar, F.W. and Owens J.B. (Eds.). C.A.B. International. Oxfordshire. United Kingdom.

Terefe, G.; Lacroux, C.; Andreoletti, O.; Grisez, C.; Prevot, F.; Bergeaud, J. P.; Penicaud, J.; Rouillon, V.; Gruner, L.; Brunel, J.C.; Francois, D.; Bouix, J.; Dorchies, P. and Jacquiet, P. 2007. Immune response to Haemonchus contortus infection in susceptible (INRA 401) and resistant (Barbados Black Belly) breeds of lambs. Parasite Immunol, 29: 415-424.

Tizard, I.R. 2009. Imunologia Veterinária. Uma Introdução. Elsevier. São Paulo. 520 pp.

Woolaston, R.R.; Barger, I.A. e Piper, L.R. 1990. Response to helminth infection of sheep selected for resistance to Haemonchus contortus. Int J Parasitol, 20: 1015-1018.

Woolaston, R.R. and Baker, R.L. 1992. Prospects of breeding small ruminants for resistance to internal parasites. Int J Parasitol, 22: 377-380. 